\title{
Betalains and phenolic compounds profiling and antioxidant capacity of pitaya (Stenocereus spp.) fruit from two species (S. Pruinosus and S. stellatus)
}

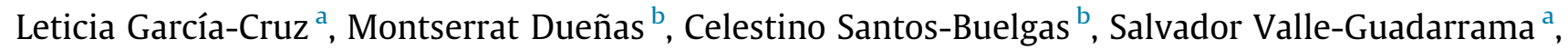 \\ Yolanda Salinas-Moreno ${ }^{\mathrm{c}, *}$ \\ ${ }^{a}$ Universidad Autónoma Chapingo, Mexico-Texcoco km 38.5, Texcoco de Mora, 56230 Mexico, Mexico \\ ${ }^{\mathrm{b}}$ Grupo de Investigación en Polifenoles, Facultad de Farmacia, Universidad de Salamanca, Campus Miguel de Unamuno (GIP-USAL), 37007 Salamanca, Spain \\ ${ }^{\mathrm{c}}$ Laboratorio de Calidad de Cultivos para Uso Humano y Pecuario, Campo Experimental Centro Altos de Jalisco, Instituto Nacional de Investigaciones Forestales, Agrícolas y \\ Pecuarias (INIFAP), Tepatitlán-Lagos de Moreno km 8, Rancho Las Cruces, Tepatitlán de Morelos 47600, Jalisco, Mexico
}

\section{A R T I C L E I N F O}

\section{Article history:}

Received 3 November 2016

Received in revised form 26 April 2017

Accepted 27 April 2017

Available online 29 April 2017

\section{Keywords:}

Phenolic acids

Antioxidant capacity

Betalains

Flavonols

Flavanones

\begin{abstract}
A B S T R A C T
Pitaya fruits (Stenocereus spp.) contain betalains and phenolic compounds that have not been completely characterized. Fruits of two ecotypes of $S$. pruinosus, red-fleshed $(S p R)$ and orange-fleshed $(S p O)$, and two of S. stellatus, red-fleshed (SsR) and white-fleshed $(S s W)$, were characterized in their betalains and phenolic compounds. The chromatographic profile of betalains was similar in $S p R, S p O$, and $S s R$, where indicaxanthin, gomphrenin I, phyllocacthin, and their isomers predominated. Betaxanthins content was higher than betacyanins and ranged from $17,706.7 \pm 1128.1$ to $22,053.6 \pm 328.1 \mu \mathrm{g} / \mathrm{g}$ dry sample. The identified phenolics mostly corresponded to hydroxycinnamoyl derivatives, flavonols and flavanones. The phenolics content was higher in S. stellatus than in S. pruinosus. The ecotype SsW, that had flesh without color, showed the highest concentration. The antioxidant capacity varied within $9.21 \pm 0.84$ and $2.41 \pm 0.36 \mu \mathrm{mol}$ Trolox/g fresh sample, as determined by the ABTS assay. By its phytochemical composition, the fruits of pitaya can be a good source of antioxidant compounds.
\end{abstract}

() 2017 Elsevier Ltd. All rights reserved.

\section{Introduction}

The genus Stenocereus includes a part of the columnar cactus species, among which S. pruinosus, S. stellatus, and S. queretaroensis, are endemic of Mexico, and the most cultivated species due to the economic value of their fruit (Bravo-Hollis \& Sánchez-Mejorada, 1991; Luna-Morales, Aguirre-Rivera, \& Peña-Valdivia, 2001). These species produce fruits named pitayas, which are poly-spermatic berries that have spherical or ovoid shape, with thorny and deciduous areoles, small and edible seeds, and juicy flesh of different colors, that vary from white, yellow, pink, orange, red or purple

Abbreviations: ABTS, 2,2'-azino-bis(3-ethylbenzothiazoline-6-sulphonic acid; $\mathrm{CE}$, collision energy; CES, collision energy spread; DAD, diode array detector; DP, declustering potential; EMS, enhanced mass spectrometer; EPI, enhanced product ion; HPLC-DAD-ESI/MS, high-performance liquid chromatographic with diode array detector and electrospray ionization and mass spectrometry; IP, input potential; $\mathrm{SpR}$, Stenocereous pruinosus red fleshed fruit; SpO, Stenocereous pruinosus orange fleshed fruit; SsR, Stenocereous stellatus red fleshed fruit; SsW, Stenocereous stellatus white fleshed fruit; TFA, trifluoroacetic acid; TE, trolox equivalent.

* Corresponding author.

E-mail address: yolasm@gmail.com (Y. Salinas-Moreno).
(Casas, Cruse-Sanders, Morales, Otero-Arnaiz, \& Valiente-Banuet, 2006). The species S. pruinosus is also known as pitaya de mayo, due to the harvest season, and it produces fruits with ovoid shape, low acidity, and total soluble solids that vary from 9 to $10^{\circ} \mathrm{Brix}$ (García-Cruz, Valle-Guadarrama, Salinas-Moreno, \& Joaquín-Cruz, 2013). On the other side, fruit of $S$. stellatus, known in Mexico as pitaya de agosto or xoconochtli, have spherical shape, a slightly acidic flesh, and similar total soluble solids to those of $S$. pruinosus (Beltrán-Orozco, Oliva-Coba, Gallardo-Velázquez, \& Osorio-Revilla, 2009). The fruits of $S$. queretaroensis have similar characteristics, although they are dehiscent, what make them very perishable (Pimienta-Barrios \& Nobel, 2004). In several references, the name pitaya has also been given to fruit of the species Hylocereus spp. (Stintzing, Schieber, \& Carle, 2002; Montoya-Arroyo et al., 2014). However, there are notable differences between plants and fruits of these two genera. In particular, the fruits of Hylocereus, named pitahayas, do not have spines, possess certain type of bracts, and their size is higher than that of the fruits of Stenocereus spp.

Color in flesh of pitaya fruit, as occurs in other cactaceae species of genera Opuntia and Hylocereus, is due to the presence of betalains (Ochoa-Velazco \& Guerrero-Beltrán, 2013), which are 
hydrosoluble pigments with nitrogen in their structure, for which about 55 different molecules have been described. Betalains are divided in two groups, betacyanins and betaxanthins, which impart red-purple and yellow-orange tonalities, respectively (Stintzing \& Carle, 2007). These pigments possess various biological activities, among which stand out their anti-inflammatory (Vidal, López-Nicolás, Gandía-Herrero, \& García-Carmona, 2014), antioxidant (Gengatharan, Dykes, \& Choo, 2015), and anti-cancer properties (Wu et al., 2006; Zou et al., 2005). Another important group of phytochemicals found in the flesh of pitaya fruit are the phenolic compounds (Beltrán-Orozco et al., 2009; García-Cruz, Salinas-Moreno, \& Valle-Guadarrama, 2012), which, like betalains, have been associated with biological activities that are beneficial to the organism, as antiallergenic, antimicrobial, antioxidant, antithrombotic, and cardioprotective (Balasundram, Sundram, \& Samman, 2006).

The antioxidant capacity of pitaya has been attributed to betalains and phenolic compounds, both present in the flesh of fruit. However, the characterization of these groups of compounds in pitaya has only been done partially (Beltrán-Orozco et al., 2009; García-Cruz et al., 2012), and such information would be valuable to conduct future works related to extraction of pigments and nutraceutical compounds, which could add value to the pitaya fruit. In this context, the objectives of the work were to characterize betalains and phenolic compounds present in the flesh of fruit of $S$. pruinosus and S. stellatus by HPLC-DAD-ESI/MS, and also to determine the antioxidant capacity of these materials.

\section{Materials and methods}

\subsection{Plant material}

Fruits of two ecotypes of $S$. pruinosus, red-fleshed $(S p R)$ and orange-fleshed $(S p O)$, and two of $S$. stellatus, red-fleshed $(S s R)$ and white-fleshed $(S s W)$ that came from homewards at Tepexi de Rodríguez, Puebla, Mexico (18 ${ }^{\circ} 35^{\prime} 46^{\prime \prime}$ N, 9755'48 W; 1644 masl) were studied. Fruits were harvested at consumption maturity, which occurs when thorns break off easily and the skin becomes shiny. A batch of 10 fruits of each variant was used, from which the skin was manually removed to obtain the flesh and this was homogenized and lyophilized.

\subsection{Flesh color}

The color of fruit flesh was determined with a colorimeter (Hunterlab, Reston, USA), using illuminant D65 and $10^{\circ}$ observer angle. Color was expressed as $L^{*}, a^{*}, b^{*}$, chroma $\left[C^{*}=\left(a^{* 2}+b^{* 2}\right)^{1 / 2}\right]$ and hue angle $\left[h^{\circ}=\arctan b^{*} / a^{*}\right]$ as described by McGuire (1992).

\subsection{Betalains analysis}

\subsubsection{Extraction}

Five hundred milligrams were weighed from each sample and mixed with $25 \mathrm{~mL}$ of a solution of methanol:TFA (trifluoroacetic acid) $1 \%$ in water $(80: 20, v / v)$. Thereafter, the mixture was placed in an ultrasonic bath (Brason, model 5510, Danbury, USA) for 30 min and allowed to stand at $-20^{\circ} \mathrm{C}$ during $3 \mathrm{~h}$. After this time, the sample was centrifuged at $28,000 \times g$ for $10 \mathrm{~min}$ at $5^{\circ} \mathrm{C}$ (Sorvall RC-5B, Newtown, USA), the supernatant was recovered, and the residue was submitted to two similar extractions, following the same conditions. The supernatants were pooled and concentrated to evaporate the methanol on a rotary evaporator (Büchi, model $\mathrm{B}-480$, Flawil, $\mathrm{CH}$ ). The extracts were re-suspended in $10 \mathrm{~mL}$ of distilled water and placed under freezing conditions until further analysis.

\subsubsection{Analysis by HPLC-DAD ESI/MS}

A high performance liquid chromatograph (HPLC, HewlettPackard 1100, Agilent Technologies, Santa Clara, USA) was used, which was equipped with a quaternary pump, autosampler, column thermostatting system, diode array detector (DAD), and a flow cell to be used with high pressures, which had connection to a mass spectrometer (MS), coupled to a HP ChemStation. The separation was carried out using a Phenomenex $5 \mu \mathrm{m}$ column $(150 \times 4.6 \mathrm{~mm})$, thermostated at $35^{\circ} \mathrm{C}$. Mobile phases were: (A) $0.1 \%$ of trifluoroacetic acid in water, and (B) pure acetonitrile. The following gradients were optimized to separate compounds: 0 to $10 \% \mathrm{~B}$ in $15 \mathrm{~min}, 10$ to $15 \% \mathrm{~B}$ in $5 \mathrm{~min}, 15$ to $18 \% \mathrm{~B}$ in $5 \mathrm{~min}$, 18 to $50 \% \mathrm{~B}$ in $10 \mathrm{~min}, 50$ to $0 \% \mathrm{~B}$ in $10 \mathrm{~min}$, followed by equilibration of the column. A flow rate of $0.5 \mathrm{~mL} / \mathrm{min}$ was used. The preferred wavelengths for detection in the DAD system were 530 and $480 \mathrm{~nm}$. In addition, the UV-Vis spectra of peaks were recorded in the range from 220 to $600 \mathrm{~nm}$.

The analysis of mass spectrometry was carried out with an API 3200 Qtrap (Applied Biosystems, Darmstadt, DE), equipped with an electrospray ionization probe (ESI) and a triple quadrupole mass analyzer that could act also as an ion trap, coupled to the software Analyst 5.1. The detection was carried out in positive ionization mode, registering mass spectra between $\mathrm{m} / \mathrm{z} 100$ and $\mathrm{m} / \mathrm{z} 1000$. Zero air at 40 psi was used as nebulizer, turbo gas at $600{ }^{\circ} \mathrm{C}$ and 50 psi to the elimination of eluent, and nitrogen at 100 psi as curtain and high collision gas. The method of full scan at high sensibility (Enhanced MS, EMS) was used for data acquisition, followed by an analysis in Enhanced Product Ion (EPI) mode to obtain the characteristic fragmentation of the majority ion obtained during the first experiment. The parameters used with EMS were: capillary voltage of $5000 \mathrm{~V}$; as potentials: declustering potential (DP), $-41 \mathrm{~V}$; input potential (EP), $7.5 \mathrm{~V}$, and collision energy (CE), $10 \mathrm{~V}$. The conditions in the EPI mode were: DP, $41 \mathrm{~V}$; EP, $7.5 \mathrm{~V} ; \mathrm{CE}$, $10 \mathrm{~V}$, and collision energy spread (CES), $0 \mathrm{~V}$.

The identification of betalains was made taking into account their retention behavior, UV-Vis spectrum, molecular ion, and mass spectrometry fragmentation pattern, which were compared with data reported previously in the literature. For quantification of betacyanins and betaxanthins standard curves were constructed with indicaxanthin and gomphrenin, both isolated in the laboratory. The indicaxanthin was isolated from flesh of $S s R$ fruit, while gomphrenin was isolated from beetroot. To do this, an extraction with methanol:TFA $1 \%$ in water $(80: 20, v / v)$ was performed, followed by fractionation with column chromatography, using silica gel C18 (Octadecyl-functionalized silica gel, Sigma Aldrich) as stationary phase and distilled water as eluent. The collected fractions containing compounds were subjected to semipreparative HPLC purification and purity was further checked by HPLC-DAD-MS. The purity of the isolated betalains was $98 \%$ and $90 \%$, for indicanxanthin and gomphrenin, respectively.

\subsection{Analysis of phenolic compounds}

\subsubsection{Extraction}

Five hundred milligrams from each sample were weighed and mixed with $25 \mathrm{~mL}$ of a solution of methanol:TFA $1 \%$ in water $(80: 20 \mathrm{v} / \mathrm{v})$. Thereafter, mixtures were placed in an ultrasonic bath during $30 \mathrm{~min}$ and left at $-20^{\circ} \mathrm{C}$ during $3 \mathrm{~h}$. Subsequently they were centrifuged at $28,000 \mathrm{~g}$ during $10 \mathrm{~min}$ at $5{ }^{\circ} \mathrm{C}$. The supernatant was recovered and the solid phase was submitted to a second similar extraction. The supernatants were pooled and concentrated to dryness on a rotary evaporator. The residue was re-dissolved in $2 \mathrm{~mL}$ of distilled water and centrifuged at 16,800 $\mathrm{g}$ (EpendursHeraeusmod. Fresco 17, Waltham, USA). The extract was deposited in a cartridge (WatersSep-Pak ${ }^{\circledR}$ Vac), which was previously activated with $2 \mathrm{~mL}$ of methanol HPLC grade, followed by $4 \mathrm{~mL}$ of 
water. In order to remove sugars, $20 \mathrm{~mL}$ of water were passed through and after that the phenolic compounds were eluted with $8 \mathrm{~mL}$ of methanol HPLC grade. This eluate was concentrated to dryness on a rotary evaporator and re-suspended in $250 \mu \mathrm{L}$ of distilled water in the case of samples of SpO and SsW, or in $500 \mu \mathrm{L}$ in the case of samples of $S s R$ and $S p R$.

\subsubsection{Analysis by HPLC-DAD-ESI/MS}

The analysis of phenolic compounds was carried out with the same HPLC-DAD-ESI/MS equipment used to characterize betalains. The separation was performed through a column Waters Spherisorb of $3 \mu \mathrm{m}(150 \times 4.6 \mathrm{~mm})$, which was thermostated at $35^{\circ} \mathrm{C}$ Mobil phases were: (A) $0.1 \%$ formic acid in water, and (B) pure acetonitrile. The following gradient was established: isocratic at $15 \% \mathrm{~B}$ for $5 \mathrm{~min}, 15$ to $20 \% \mathrm{~B}$ in $5 \mathrm{~min}, 20$ to $25 \% \mathrm{~B}$ in $10 \mathrm{~min}, 25$ to $35 \% \mathrm{~B}$ in $10 \mathrm{~min}, 35$ to $10 \% \mathrm{~B}$ in $10 \mathrm{~min}$, followed by column equilibration. A flow of $0.5 \mathrm{~mL} / \mathrm{min}$ was applied. The preferred wavelengths for detection in the DAD were 280 and $370 \mathrm{~nm}$, and the UV-Vis spectra of peaks in the range 220 to $600 \mathrm{~nm}$ were recorded (Barros, Dueñas, Carvalho, Ferreira, \& Santos-Buelga, 2012).

The analysis by mass spectrometry was performed under the same conditions described for betalains, except that detection was used in negative ionization mode. The identification of phenolic compounds was made according to their retention times, UV-Vis spectra, pseudomolecular ions, and the mass spectrometry fragmentation patterns. The quantification of individual phenolic compounds was based on standard curves of caffeic acid, ferulic acid, $p$-coumaric acid, taxifolin, naringenin, quercetin 3-O-rutinoside, isorhamnetin 3-O-glucoside, and kaempferol-3-Oglucoside.

\subsection{Antioxidant capacity}

To evaluate the antioxidant capacity (AC) of pitaya fruits, the extraction of betalains was done according to Wu et al. (2006). Briefly, two grams of macerated fruit pulp and $20 \mathrm{~mL}$ of $80 \%$ aqueous methanol were placed in an Erlenmeyer flask and sonicated for $10 \mathrm{~min}$ in an ultrasonic bath. Afterwards the sample was stirred for $20 \mathrm{~min}$, and centrifuged at $2200 \mathrm{~g}$ for $10 \mathrm{~min}$, to recover the supernatant. The residue was extracted again under the same conditions. The supernatants were combined and adjusted to a defined volume with the extraction solvent. The ABTS method was chosen since it has been used to measure the AC of several fruits from the Cactaceae family such as fruits of Hylocereus (Wu et al., 2006) and Opuntia (Butera et al., 2002). The AC assay consisted of a $7 \mathrm{mM}$ solution of ABTS (2,2'-azino-bis(3-ethylbenzothiazoline-6-sulpho nic acid) in distilled water and another one of $2.45 \mathrm{mM}$ of potassium persulfate $\left(\mathrm{K}_{2} \mathrm{~S}_{2} \mathrm{O}_{8} ; \mathrm{PP}\right)$ were prepared and combined in 2:1 ratio. The mixture was left in darkness during $16 \mathrm{~h}$ to allow generation of free radicals. Thereafter, dilution with a 7.4-pH phosphate buffer was made until an absorbance of $0.7 \pm 0.001$ at $734 \mathrm{~nm}$ was obtained (Wu et al., 2006). In order to determine the antioxidant capacity, $200 \mu \mathrm{L}$ of betalains extract were placed in a quartz cell together with $2800 \mu \mathrm{L}$ of the mixture ABTS-PP, and the absorbance was measured with a spectrophotometer (PerkinElmer Lambda 25
UV/Vis) each minute along $7 \mathrm{~min}$. The reduced $A B T S$ was evaluated with the calculation [\%ABTS reduced $\left.^{=},\left[\left(\mathrm{Abs}_{0}-\mathrm{Abs}_{\mathrm{n}}\right) / \mathrm{Abs}_{0}\right]^{*} 100\right]$, where $\mathrm{Abs}_{0}$ is the absorbance of the blank ( $200 \mu \mathrm{L}$ of phosphate buffer plus $2800 \mu \mathrm{L}$ of ABTS-PP) and $\mathrm{Abs}_{n}$ is the absorbance of the sample at the time $t$. In addition, a standard curve of Trolox ( (士)-6-hydroxy-2,5,7,8-tetramethylchromane-2-carboxylic acid) was prepared and results were expressed as $\mu \mathrm{mol}$ Trolox equivalents per gram of fresh pulp ( $\mu \mathrm{mol} \mathrm{TE} / \mathrm{g} \mathrm{FP})$.

\subsection{Data analysis}

An analysis of variance complemented with routines of comparison of means (Tukey, $p<0.05$ ) was performed to determine whether significant differences exist between ecotypes studied. Data were analyzed with the SAS statistical package.

\section{Results and discussion}

\subsection{Color characteristics}

The ecotype with the highest luminosity was $S s W$, which was attributed to the lack of betalains. Such ecotype was followed by $S p O$ and $S p R$, and finally by $S s R$. The fruit of pitaya with white flesh $(S s W)$ was distinguished by low values in $\mathrm{a}^{*}, \mathrm{~b}^{*}$ and $\mathrm{C}^{*}$, and high value in $h_{a b}$. The low value in $C^{*}$ could be related with the presence of seeds with black color in the flesh of this fruit. The fruit of SpO showed a bright color with red-orange tonality, according to the observed values of $\mathrm{L}^{*}, \mathrm{C}^{*}$, and $\mathrm{h}_{\mathrm{ab}}$. Values of $\mathrm{a}^{*}, \mathrm{~b}^{*}, \mathrm{~h}_{\mathrm{ab}}$, and $\mathrm{C}^{*}$ were different (Table 1 ). The pitaya $S p R$ showed a red-pink tint, with higher value in $C^{*}$ than $S s R$, which is associated with higher color purity. On the other side, $S s R$ has red-purple flesh, with low value in $C^{*}$ and, therefore, the color purity is lesser than that of $S p R$.

\subsection{Betalains identification}

The analysis by HPLC allowed to separate up to 11 betalains in the analyzed samples (Fig. 1). The highest diversity was observed in the group of betacyanins (Fig. 1A), to which nine compounds were associated, and these could be tentatively identified from their mass and UV-Vis spectra, while the other two compounds (peaks 1 and 2) were identified as betaxanthins (Fig. 1B). The three analyzed ecotypes of fruit showed similar profile, with differences only in the relative proportion of each betalain. A higher diversity has been reported in fruit of Hylocereus polyrhizus (Esquivel, Stintzing, \& Carle, 2007; Zou et al., 2005). In the case of fruit of Opuntia spp., Castellanos-Santiago and Yahia (2008) and CejudoBasante, Chalaal, Louaileche, Parrado and Heredia (2014) reported higher diversity of betaxanthins than betacyanins. However, Stintzing et al. (2005) reported higher number of betacyanins than betaxanthins. The proportion of these two groups of betalains and the particular type inside each group has impact in the color of fruit of the Opuntia genus (Castellanos-Santiago \& Yahia, 2008).

Peak 1 and 2 presented $\lambda_{\max }$ at $478 \mathrm{~nm}$ and an $[\mathrm{M}+\mathrm{H}]^{+}$ion at $\mathrm{m} / \mathrm{z} 309$ releasing an $\mathrm{MS}^{2}$ fragment at $\mathrm{m} / \mathrm{z} 263$, which was coherent

Table 1

Color parameters in fruits of the ecotypes orange ( $S p O)$ and red (SpR) of S. pruinosus, and red (SsR) and white (SsW) of S. stellatus.

\begin{tabular}{|c|c|c|c|c|c|}
\hline Ecotypes & $\mathrm{L}^{*}$ & $\mathrm{a}^{*}$ & $\mathrm{~b}^{*}$ & $\mathrm{~h}_{a b}\left({ }^{\circ}\right)$ & $C^{*}$ \\
\hline SpO & $27.85 \pm 7.31 b$ & $35.30 \pm 4.74 \mathrm{a}$ & $24.72 \pm 1.54 a$ & $35.28 \pm 4.83 b$ & $43.21 \pm 3.62 a$ \\
\hline SpR & $20.82 \pm 2.51 b$ & $28.54 \pm 7.00 \mathrm{~b}$ & $11.81 \pm 1.97 b$ & $22.87 \pm 3.12 c$ & $30.92 \pm 7.058$ \\
\hline SsR & $15.73 \pm 1.44 \mathrm{c}$ & $9.70 \pm 2.75 c$ & $2.74 \pm 0.94 c$ & $15.50 \pm 1.47 \mathrm{~d}$ & $10.08 \pm 2.90 \mathrm{c}$ \\
\hline SsW & $41.98 \pm 2.76 a$ & $-0.35 \pm 0.18 d$ & $4.08 \pm 0.91 c$ & $95.29 \pm 2.51 \mathrm{a}$ & $4.10 \pm 0.98 c$ \\
\hline
\end{tabular}

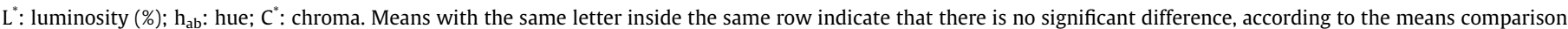
routines (Tukey, $\mathrm{p}<0.05$ ). 

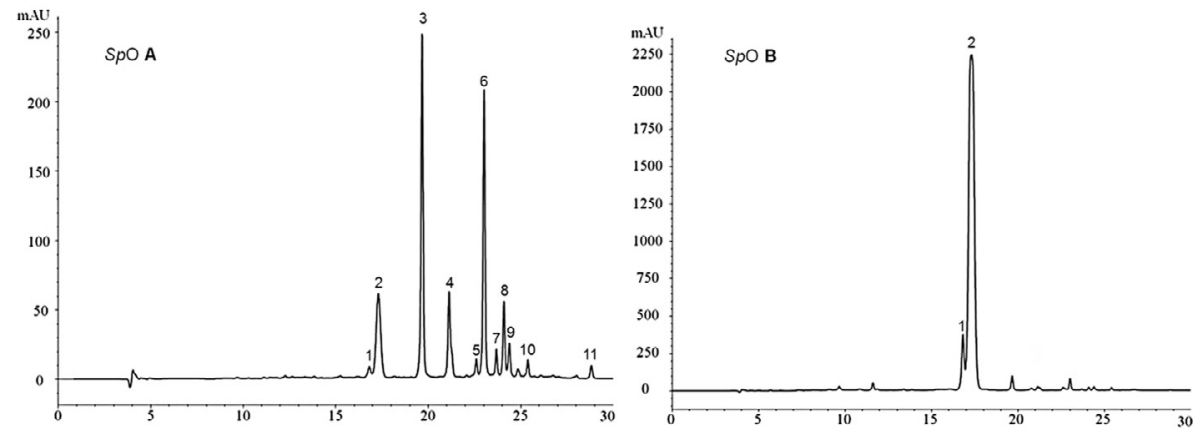

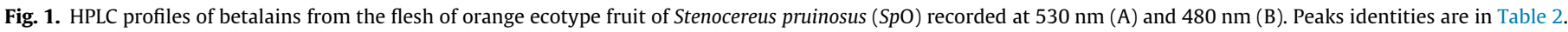

with the compounds proline-betaxanthin (indicaxanthin) and its isomer, isoindicaxanthin. Indicaxanthin is a very common betalain that is present in cactus pear (Opuntia ficus-indica) (CastellanosSantiago \& Yahia, 2008; Cejudo-Bastante, Chalaal, Louaileche, Parrado, \& Heredia, 2014).

Peaks 3 and 4 presented $\lambda_{\max }$ at $536-538 \mathrm{~nm}$ and an $[\mathrm{M}+\mathrm{H}]^{+}$ ion at $m / z 551$ releasing an $\mathrm{MS}^{2}$ fragment at $m / z 389(-162 \mathrm{mu}$, loss of a hexosyl moiety), pointing to they corresponded to betanidin-glucosides, a type of dopamine-derived betalains (Kobayashi, Schmidt, Wray, \& Schliemann, 2001; Strack, Vogt, \& Schliemann, 2003). An identity as (iso)betanin [i.e., (iso) betanidin-5-O- $\beta$-glucoside] was discarded by comparison with a betalain extract from beetroot. Thus, these compounds were assigned as gomphrenin-I [betanidin-6-O- $\beta$-glucoside] and isogomphrenin-I [isobetanidin-6-O- $\beta$-glucoside], respectively, which have also been reported in purple pitahaya fruit (i.e., Hylocereus spp.) (Cai, Xing, Sun, \& Corke, 2006; Esquivel et al., 2007) and cactus pear (Opuntia spp.) (Castellanos-Santiago \& Yahia, 2008; Stintzing et al., 2005).

Peaks 5, 9 and 11, showing $\lambda_{\max }$ at $498-516 \mathrm{~nm}$, were associated as 2-descarboxy-betanidin derivatives (Kobayashi et al., 2001; Strack et al., 2003). Peak 5 presented an $[\mathrm{M}+\mathrm{H}]^{+}$ion at $\mathrm{m} /$ $z$ 507, 44 mu lower than betanin, i.e., less a carboxylic group, and released an $\mathrm{MS}^{2}$ fragment at $m / z 345$ ( $-162 \mathrm{mu}$, loss of a hexosyl moiety). This allowed its tentative identification as 2-descarboxybetanin, reported in beetroot (Kobayashi et al., 2001; Strack et al., 2003), but also in some Cactaceae (Morales, Barros, Ramirez-Moreno, Santos-Buelga, \& Ferreira, 2015). Peak 9 and 11 showed $[\mathrm{M}+\mathrm{H}]^{+}$at $m / z 593,86$ mu greater than peak 5, suggesting the presence of an additional malonyl residue, and produced $\mathrm{MS}^{2}$ fragments at $\mathrm{m} / \mathrm{z} 549$ ( $-44 \mathrm{mu}$, loss of $\mathrm{CO}_{2}$; carboxylic moiety), 507 ( $-86 \mathrm{mu}$, loss of a malonyl residue) and 345 ( $-162-86 \mathrm{mu}$, loss of a malonylhexoside residue), which allowed their identification as malonyl-2-descarboxy-betanin isomers. Although, the linkage of the malonyl residue cannot be attributed from the mass spectra, substitution at the $6{ }^{\prime}-O$-position of the glucose was assumed, as previously has been described (Kobayashi et al., 2001; Strack et al., 2003). Thus, the compounds were tentatively assigned as 6'-O-malonyl-2-descarboxy-betanin [2-descarboxybetanidin 5-O-(6'-O-malonyl- $\beta$-D-glucoside $)]$ and $6^{\prime}-O$-malonyl-2descarboxy-isobetanin, respectively, considering their relative order of elution with isobetanin eluting later than betanin [e.g., $7,20,22,25,27])$.

Peaks 6,7 and 8 showed similar absorption spectra with $\lambda_{\max }$ at $536-538 \mathrm{~nm}$ and the same $\mathrm{m} / \mathrm{z}$ value $[\mathrm{M}+\mathrm{H}]^{+}$at $637,86 \mathrm{mu}$ greater than betanin. These features are coherent with malonylbetanin isomers, pigments that are characteristic of flowers and fruits of Cactaceae (Kobayashi et al., 2001; Strack et al., 2003), and that have been reported in fruits from red-purple pitahaya (Hylocereus polyrhizus) (Stintzing et al., 2002; Cai et al., 2006;
Wybraniec, Nowak-Wydra, Mitka, Kowalski, \& Mizrahi, 2007). Based on their abundance in the extracts and relative elution order, peaks 6 and 8 were tentatively identified as phyllocactin [betanidin $5-O-\left(6^{\prime}-O\right.$-malonyl- $\beta$-D-glucoside)] and isophyllocactin [isobetanidin 5-O-(6'-O-malonyl- $\beta$-D-glucoside $)]$, respectively. Minority peak 7 might correspond to betanidin-5-O-(6'-O-3-hydroxy-butyryl)- $\beta$ glucoside (Stintzing et al., 2002) or 4'-O-malonyl-betanin (Wybraniec, Stalica, Spórna, \& Mizrahi, 2010), betacyanins that have also been reported in purple pitaya. Peak $10\left([\mathrm{M}+\mathrm{H}]^{+}\right.$at $\mathrm{m} /$ $z$ 651) would correspond to a betanidin derivative, as revealed by the $\mathrm{MS}^{2}$ fragment ion produced at $m / z 389$, although no further support could be obtained to propose an identity.

\subsection{Quantification of betalains by HPLC}

The quantification of betalains is commonly performed by spectrophotometry and using a calculation where the absorbance is taking into account, besides to the molar extinction coefficient, and the molecular weight of betanin, in the case of betacyanins, or indicaxanthin, in the case of betaxanthins (CastellanosSantiago \& Yahia, 2008). In the present work, each of the identified betaxanthins and betacyanins were quantified from the area under the curve of peaks obtained in chromatograms of HPLC-DAD detected at $480 \mathrm{~nm}$ and $530 \mathrm{~nm}$, respectively, by comparison with standard curves of indicaxanthin (betaxanthins) and gomphrenin I (betacyanins). The content of betacyanins was lower than betaxanthins in the three ecotypes analyzed (Table 2). Largest diversity and content of betacyanins were found in the red fruit samples. Values ranged from $165.1 \pm 7.0$ to $5423.4 \pm 135.3 \mathrm{mg} / \mathrm{g}$ dry weight (DW), with the greatest $(\mathrm{p} \leq 0.05)$ quantities found in the ecotype $S p R$. The main difference between red ecotypes was observed in the contents of gomphrenin I and isogomphrenin I, which were higher $(\mathrm{p} \geq 0.05)$ in $S p R$ in relation to $S s R$. In the orange fruit $(S p O)$ only three betacyanins (isogomphrenin I, phyllocactin and isophyllocactin) were detected, with contents that were significantly lower than those observed in red fruits, and with dominance of phyllocactin.

Betaxanthins were found in much greater levels than betacyanins, with values ranging between 17,706.7 \pm 1128.1 and $22,053.5 \pm 329.1 \mu \mathrm{g} / \mathrm{g}$ DW, but without statistical differences between the analyzed ecotypes ( $S p O, S p R$, and $S s R)$. The content of betacyanins obtained for the fruits of the three analyzed Stenocereus spp. ecotypes were comparable to those reported by Castellanos-Santiago and Yahia (2008) in the flesh of 10 cultivars of Opuntia spp., who determined values that varied from 50 to $5290 \mu \mathrm{g} / \mathrm{g}$ of dry flesh, using water as extraction solvent. These authors also reported values of betaxanthins between 120 and $2860 \mu \mathrm{g} / \mathrm{g}$ of dry pulp, well below than the ones obtained in the present study. Cejudo-Bastante et al. (2014) analyzed betalains in the fruit of three cultivars of 0 . ficus indica [L.] Mill using aqueous 
Table 2

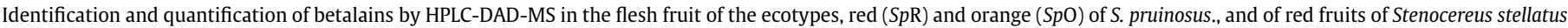
(SsR). Concentrations are in $\mu \mathrm{g} / \mathrm{g}$ DW.

\begin{tabular}{|c|c|c|c|c|c|c|c|c|c|}
\hline Peak & $\begin{array}{l}\mathrm{Rt} \\
(\mathrm{min})\end{array}$ & $\begin{array}{l}\lambda_{\max } \\
(\mathrm{nm})\end{array}$ & $\begin{array}{l}{[\mathrm{M}+\mathrm{H}]^{+}} \\
(m / z)\end{array}$ & $\operatorname{MS}^{2}(m / z)$ & Tentative identity & References ${ }^{*}$ & SpO & $S p R$ & SsR \\
\hline \multicolumn{10}{|c|}{ Betacyanins } \\
\hline 3 & 19.6 & 536 & 551 & 389 & Gomphrenin I & $1,2,4,5,8,9$ & $\mathrm{t}$ & $3276.08 \pm 9.24 a$ & $509.09 \pm 19.60 b$ \\
\hline 4 & 21.1 & 538 & 551 & 389 & Isogomphrenin I & $1,2,4,5,8,9$ & $36.92 \pm 7.4 b$ & $972.57 \pm 69.25 a$ & $59.70 \pm 5.65 b$ \\
\hline 5 & 22.7 & 498 & 507 & 345 & 2-descarboxy-betanin & $5,6,9$ & $\mathrm{t}$ & $65.69 \pm 26.18 a$ & $\mathrm{t}$ \\
\hline 6 & 23.1 & 536 & 637 & $593,551,389$ & Phyllocactin & $1,5,7,9,10$ & $109.11 \pm 0.33 b$ & $798.38 \pm 57.6 a b$ & $1449.66 \pm 273.24 a$ \\
\hline 7 & 23.8 & 536 & 637 & - & $\begin{array}{l}\text { 4'-O-malonyl-betanin or betanidin- } \\
5-O-\left(6^{\prime}-O-3 \text {-hydroxy-butyryl)- } \beta-\right. \\
\text { glucoside }\end{array}$ & $1,5,7,9,10,11$ & $\mathrm{t}$ & $9.20 \pm 4.54 b$ & $53.95 \pm 13.98 a$ \\
\hline 8 & 24.2 & 538 & 637 & $593,551,389$ & Isophyllocactin & $1,5,7,9,10$ & $16.05 \pm 0.7 b$ & $190.60 \pm 7.02 \mathrm{ab}$ & $269.97 \pm 63.82 \mathrm{a}$ \\
\hline 9 & 24.5 & 512 & 593 & $549,507,345$ & $\begin{array}{l}6^{\prime}-O \text {-malonyl-2-descarboxy- } \\
\text { betanin }\end{array}$ & 5,9 & $\mathrm{t}$ & $42.19 \pm 2.74 a$ & $35.69 \pm 5.32 a$ \\
\hline 10 & 25.4 & 514 & 651 & 389 & Betanidin derivative & & $\mathrm{t}$ & $55.66 \pm 18.35 a$ & $68.65 \pm 46.74 a$ \\
\hline 11 & 28.9 & 516 & 593 & $549,507,345$ & $\begin{array}{l}\text { 6'-O-malonyl-2-descarboxy- } \\
\text { isobetanin }\end{array}$ & 5,9 & $\mathrm{t}$ & $\mathrm{t}$ & $79.08 \pm 2.52 \mathrm{a}$ \\
\hline Total & betacya & nins & & & & & $162.07 \pm 7.03 c$ & $5423.38 \pm 135.32 a$ & $2525.82 \pm 326.76 b$ \\
\hline \multicolumn{10}{|c|}{ Betaxanthins } \\
\hline 1 & 16.9 & 478 & 309 & 263,235 & Isoindicaxanthin & 2,3 & $1158.64 \pm 147.34 a$ & $1143.38 \pm 148.42 a$ & $1026.44 \pm 179.65 a$ \\
\hline 2 & 17.4 & 478 & 309 & 263,235 & Indicaxanthin & 2,3 & $20894.82 \pm 181.76 a$ & $16563.32 \pm 979.68 a$ & $20970.47 \pm 2363.25 a$ \\
\hline \multicolumn{7}{|c|}{ Total betaxanthins } & $22053.46 \pm 329.09 a$ & $17706.72 \pm 1128.12 \mathrm{a}$ & $21681.66 \pm 1097.06 a$ \\
\hline
\end{tabular}

Means with the same letter inside the same row indicate that there is no significant difference, according to the means comparison routines (Tukey, $\mathrm{p}<0.05)$ t: traces.

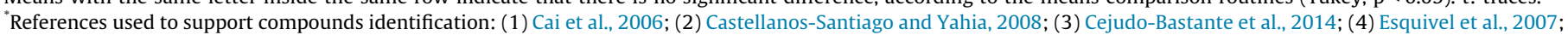

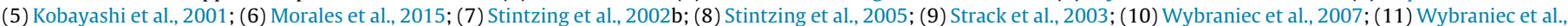
2010.

methanol as solvent and reported levels of betaxanthins well above of betacyanins. Nevertheless, they do not actually quantified the compounds, as they just expressed the level of the different betalains identified through the area under the curve of each peak and, due to this, it is not possible to make a strict comparison with the results obtained herein. However, the ratio betaxanthins/betacyanins resulted in values that ranged from 34.03 in the case of red cultivar, to 170.9 in yellow-fleshed cultivars. In the case of fruit of Stenocereus of the present work the ratio between both groups (betaxanthins/betacyanins) was $136.07,3.26$, and 8.8, for $S p O$, $S s R$, and $S p R$, respectively. Fathordoobady, Mirhosseini, Selamat, and Abd Manap (2016) showed that the amount of betalains extracted from $H$. polyrhizus doubled when the solvent was modified from water to a mixture of ethanol:water $(90: 10 \mathrm{v} / \mathrm{v})$. PérezLoredo, García-Ochoa, and Barragán-Huerta (2015) reported contents of betacyanins in fruits of Stenocereus stellatus with orange and red flesh of $135.2 \pm 3.5$ and $1457.2 \pm 55.2 \mu \mathrm{g}$ of betanin per gram of dry sample, respectively. In addition, the contents of betaxanthins in these materials were $928.7 \pm 11.9$ and $1511.3 \pm 62.2 \mu \mathrm{g}$ of indicaxanthin per gram of dry flesh. Data for betacyanins are similar to those obtained in the present work, but those of betaxanthins are far below. Indeed, it becomes clear that the solvent used for the extraction played an important role in the recovery of betalains from cactus fruit. It is to say that in most of the reported studies, betalains have been extracted with water and they have been quantified by spectrophotometry, due to the lack of standards.

The predominance of any betalain in fruit of cactus varies among genera. The fruits of $H$. polyrhizus have betanin and phyllocactin as predominant betalains (Wybraniec et al., 2001). In Opuntia spp. the dominant betalain depends on the color of the fruit; in materials with purple color in flesh, as cultivar Camuesa, the predominant betalains are betanin and indicaxanthin (CastellanosSantiago \& Yahia, 2008).

\subsection{Analysis of phenolic compounds}

Identification and quantification of individual phenolic compounds of S. pruinosus and S. stellatus were performed by HLC-
DAD-ESI/MS. Up to thirteen compounds of five different phenolic classes could be detected and tentatively identified based on their retention time and absorption and mass spectra (Table 3 ). Among them, quercetin 3-O-rutinoside (peak 8) and isorhamnetin 3-Oglucoside (peak 12) were positively identified by comparison with commercial standards.

Peaks 1, 3, 4, and 5 showed UV spectra that coincided with hydroxycinnamoyl derivatives. Compounds 1 and 3 possessed the same pseudomolecular ion $[\mathrm{M}-\mathrm{H}]^{-}$at $m / z 341$, yielding $\mathrm{MS}^{2}$ product ions at $m / z 179 \mathrm{mu}$ ([caffeic acid-H]-, from the loss of a hexosyl moiety, $162 \mathrm{mu}$ ) and 135 ([caffeic acid- $\left.\mathrm{H}-\mathrm{CO}_{2}\right]^{-}$), which allowed assigning them as caffeoyl hexosides. Similarly, peak 4 $[\mathrm{M}-\mathrm{H}]^{-}$at $m / z$ 517) was identified as a feruloyl dihexoside based on the production of the fragment ions at $\mathrm{m} / \mathrm{z} 193 \mathrm{mu}$ ([ferulic acid-H $]^{-}$; loss of two hexosyl moieties, $324 \mathrm{mu}$ ) and 149 ([ferulic acid- $\left.\left.\mathrm{H}-\mathrm{CO}_{2}\right]^{-}\right)$. Peak 5 showed a precursor ion $[\mathrm{M}-\mathrm{H}]^{-}$at $\mathrm{m} / z 337$ and $\mathrm{MS}^{2}$ product ions at $m / z 191$ ([quinic acid-H] ${ }^{-}$), 173 ([quinic acid- $\left.\mathrm{H}-\mathrm{H}_{2} \mathrm{O}\right]^{-}$), 163 ([coumaric acid- $\left.\mathrm{H}\right]^{-}$) and 145 ([coumaric acid- $\left.\mathrm{H}_{-} \mathrm{H}_{2} \mathrm{O}\right]^{-}$), which allowed its identification as a coumaroylquinic acid.

Compounds $9\left([\mathrm{M}-\mathrm{H}]^{-}\right.$at $\left.m / z 447\right)$ and $11\left([\mathrm{M}-\mathrm{H}]^{-}\right.$at $\left.m / z 623\right)$ showed absorption spectra characteristic of flavonols and were identified as kaempferol and isorhamnetin hexosides based on the aglycone fragment ions observed at $m / z 285$ and 315, respectively, from the loss of a hexosyl residue in both cases. The pseudomolecular ion of peak 11 was the same as isorhamnetin3-O-glucoside, suggesting that peak 12 might be the corresponding galactoside, typically eluting before the equivalent glucoside in RP-HPLC (Santos-Buelga, García-Viguera, \& Tomás-Barberán, 2003); nonetheless, the possibility of being a glucoside substituting other position of the isorhamnetin cannot be discarded either. Peaks $6\left([\mathrm{M}-\mathrm{H}]^{-}\right.$at $\left.\mathrm{m} / \mathrm{z} 449\right), 11\left([\mathrm{M}-\mathrm{H}]^{-}\right.$at $\left.\mathrm{m} / \mathrm{z} 491\right)$ and 13 $\left([\mathrm{M}-\mathrm{H}]^{-}\right.$at $\mathrm{m} / z$ 475) showed UV spectra characteristic of flavanones and were assigned as eridictyol-O-hexoside, eridictyol$O$-acetylhexoside, and naringenin- $O$-acetylhexoside, respectively, according to their pseudomolecular ions and $\mathrm{MS}^{2}$ fragments produced form the loss of hexosyl $(-162 \mathrm{mu})$ or acetylhexoside $(-162+42 \mathrm{mu})$ moieties. Compound 7 was identified as taxifolin acetylhexoside, owing to its UV spectrum typical of a dihy- 
Table 3

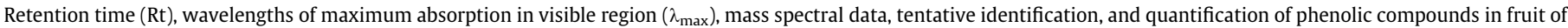
S. pruinosus (SpR: red flesh ecotype, SpO: orange flesh ecotype) and S. stellatus (SsR: red flesh ecotype and SsB: white flesh ecotype). Concentrations are in $\mu \mathrm{g} / \mathrm{g}$ DW.

\begin{tabular}{|c|c|c|c|c|c|c|c|c|c|c|}
\hline Peak & $\begin{array}{l}\text { Rt } \\
(\min )\end{array}$ & $\begin{array}{l}\lambda_{\max } \\
(\mathrm{nm})\end{array}$ & $\begin{array}{l}{[\mathrm{M}+\mathrm{H}]^{+}} \\
(m / z)\end{array}$ & $\operatorname{MS}^{2}(m / z)$ & Tentative identity & References ${ }^{*}$ & SpO & SpR & SsR & SsW \\
\hline \multicolumn{11}{|c|}{ Hydroxycinnamoyl derivatives } \\
\hline 1 & 7.4 & 316 & 341 & 179,135 & Caffeoyl hexoside I & $1,2,4$ & $17.48 \pm 2.31 b$ & $35.4 \pm 3.61 \mathrm{a}$ & $18.09 \pm 0.28 b$ & $14.07 \pm 0.72 b$ \\
\hline 3 & 8.8 & 316 & 341 & 179,135 & Caffeoyl hexoside II & $1,2,4$ & $7.91 \pm 0.83 \mathrm{~b}$ & $23.94 \pm 2.2 \mathrm{a}$ & $13.93 \pm 2.04 b$ & $12.69 \pm 0.68 b$ \\
\hline 4 & 11.1 & 316 & 517 & 193,149 & Feruloyl dihexoside & $1,2,3,4$ & $8.80 \pm 1.13 b$ & nd & $28.37 \pm 7.92 \mathrm{a}$ & $45.24 \pm 5.55 a$ \\
\hline 5 & 12 & 300 & 337 & $191,173,163,145$ & $\begin{array}{l}p \text {-coumaroyl quinic } \\
\text { acid }\end{array}$ & 1,4 & $7.51 \pm 0.10 \mathrm{~d}$ & $12.14 \pm 0.08 \mathrm{c}$ & $15.61 \pm 0.54 b$ & $19.97 \pm 0.52 \mathrm{a}$ \\
\hline \multicolumn{7}{|c|}{ Total hydroxycinnamoyl derivatives } & $41.7 \pm 1.09$ & $71.48 \pm 1.96$ & $76.0 \pm 2.69$ & $91.97 \pm 1.86$ \\
\hline \multicolumn{11}{|c|}{ Flavonols } \\
\hline 8 & 19.4 & 352 & 609 & 301 & $\begin{array}{l}\text { Quercetin 3-O- } \\
\text { rutinoside }\end{array}$ & & $4.16 \pm 0.17 b$ & $2.91 \pm 0.13 b$ & $7.09 \pm 0.17 \mathrm{a}$ & $7.19 \pm 0.54 a$ \\
\hline 9 & 20.7 & 348 & 447 & 285 & Kaempferol hexoside & & nd & nd & $3.50 \pm 0.24 a$ & $4.06 \pm 0.25 a$ \\
\hline 11 & 23.4 & 356 & 623 & 315 & Isorhamnetin hexoside & & $1.31 \pm 0.13 \mathrm{a}$ & $1.17 \pm 0.14 \mathrm{a}$ & nd & nd \\
\hline 12 & 24 & 356 & 623 & 315 & $\begin{array}{l}\text { Isorhamnetin 3-O- } \\
\text { glucoside }\end{array}$ & & $1.29 \pm 0.01$ & nd & nd & nd \\
\hline $\begin{array}{r}\text { Total } \\
\text { fla }\end{array}$ & onols & & & & & & $6.76 \pm 0.10$ & $4.08 \pm 0.13$ & $10.59 \pm 0.20$ & $11.25 \pm 0.39$ \\
\hline \multicolumn{11}{|c|}{ Flavanones } \\
\hline 6 & 17.2 & 284 & 449 & 287 & Eriodictyol hexoside & & nd & nd & $8.98 \pm 1.33 a$ & nd \\
\hline 10 & 22.4 & 284 & 491 & 287 & $\begin{array}{l}\text { Eriodictyol } \\
\text { acetylhexoside }\end{array}$ & & nd & nd & $12.31 \pm 0.99 a$ & $16.25 \pm 1.77 a$ \\
\hline 13 & 27.6 & 282 & 475 & 271 & $\begin{array}{l}\text { Naringenin } \\
\text { acetylhexoside }\end{array}$ & & nd & nd & $5.91 \pm 0.07 a$ & nd \\
\hline $\begin{array}{r}\text { Total } \\
\text { fla }\end{array}$ & ranones & & & & & & & & $14.89 \pm 0.79$ & $16.25 \pm 1.77$ \\
\hline \multicolumn{11}{|c|}{ Others } \\
\hline 2 & 8 & 278 & 137 & 119 & Tyrosol & & $\begin{array}{l}\text { Not } \\
\text { quantified }\end{array}$ & & & \\
\hline 7 & 18.2 & 296 & 507 & 303 & $\begin{array}{l}\text { Taxifolin } \\
\text { acetylhexoside }\end{array}$ & & $5.25 \pm 0.55 b$ & nd & $8.02 \pm 1.43 b$ & $21.08 \pm 2.56 a$ \\
\hline $\begin{array}{r}\text { Total } \\
\text { col }\end{array}$ & $\begin{array}{l}\text { henolic } \\
\text { npounds }\end{array}$ & & & & & & $53.75 \pm 2.95 b$ & $75.58 \pm 1.61 b$ & $121.86 \pm 8.11 \mathrm{a}$ & $140.59 \pm 9.06 a$ \\
\hline
\end{tabular}

Means with the same letter inside the same row indicate that there is no significant difference, according to the means comparison routines (Tukey, $\mathrm{p}<0.05)$. nd: not detected.

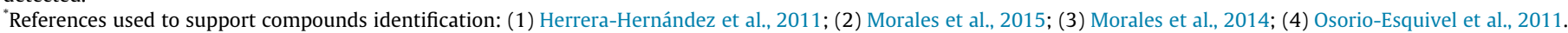

droflavonol and its pseudomolecular ion $[\mathrm{M}-\mathrm{H}]^{-}$at $m / z 507$, releasing a $\mathrm{MS}^{2}$ fragment at $m / z 303(-162+42 \mathrm{mu})$. Finally, absorption and mass characteristics spectra of peak 2 and its comparison with a commercial standard allowed its identification as tyrosol, a widespread phenolic alcohol. The remaining peaks that can be observed in the HPLC chromatograms (Fig. 2) could not be assigned, although they might not correspond to phenolic compounds.

Phenolic acid derivatives and flavonols were present in the four ecotypes fruit of Stenocereus, which did not occur with flavanones that were present only in the fruits of S. stellatus (Table 3). The derivatives of caffeic acid (caffeoyl hexoside I and II) and $p$ coumaroylquinic acid were common in the four type of fruit analyzed, while feruloyl dihexoside was present only in three $(\mathrm{SpO}$, $S s R$, and $S s W$ ). Caffeoyl hexoside has been reported by Morales et al. (2015) to be present in joconostle (Opuntia matudae Scheinvar) $\mathrm{cv}$. Rosa. Among flavonoids, quercetin 3-O rutinoside was present in the four ecotypes of fruit, but in smaller amounts in SpO and $S p R$. This flavonol, besides isorhamnetin 3-O-glucoside and isorhamnetin hexoside, have been identified in Opuntia joconostle (Morales, Barros, Ramirez-Moreno, Santos-Buelga, \& Ferreira, 2014). Flavanones were present only in the fruit of S. stellatus species ( $S s R$ and $S s W$ ). There are no reports about the presence of flavanones in fruit of cacti species. In fruits of 0 . joconostle, $O$. macrorhiza and Myrtillocactus sp. both phenolic acids and flavonols have been identified (Osorio-Esquivel, Ortiz-Moreno, Álvarez, Dorantes-Álvarez,\& Giusti, 2011; Herrera-Hernández, GuevaraLara, Reynoso-Camacho, \& Guzmán-Maldonado, 2011). Particularly, in the mesocarp and endocarp of 0 . matudae, many flavonols have been identified, but only one phenolic acid derivative (ferulic acid glucoside) (Morales et al., 2015; Morales et al., 2014). Other phenolic acids that were identified in 0 . joconostle were protocatechuic, vanilic, 4-hydroxybenzoic, and hydroxycinnamic acids (Osorio-Esquivel, Ortiz-Moreno, Álvarez, Dorantes-Álvarez, \& Giusti, 2011). In Myrtillocactus sp. caffeic and gallic acids (Guzmán-Maldonado et al., 2010), as well as protocatechuic acid and ellagic acid (Herrera-Hernández et al., 2011) have been described.

Among the four ecotypes studied, the white fruit of S. stellatus had the highest numerical value in total phenolic compounds, although it was statistically equal $(\mathrm{p}>0.05)$ to the fruit with red flesh $(S p R)$, which in turn was equal to $S s R$. The fruit with orange flesh $(\mathrm{SpO})$ had the lowest content. In the Hylocereus genus, higher content of total phenolics in a species with intense red color $(H$. polyrhizus) than the white species ( $H$. undatus) have been reported (Suh et al., 2014). However, those authors performed the quantification of total phenolics with the Folin-Ciocalteu method, so in the red fruit the value could have been overestimated, since aromatic rings of betalains can react with the Folin-Ciocalteu reagent, as well as with other reducing substances present in the extracts.

\subsection{Antioxidant capacity}

The antioxidant capacity (AC) among the four ecotypes of fruit analyzed was different. The fruit of $S$. stellatus with red flesh (SsR) had the highest AA $(9.21 \pm 0.84 \mu \mathrm{mol} \mathrm{TE} / \mathrm{g}$ fresh pulp) followed by $\operatorname{SpR}(6.80 \pm 0.33)$. The lesser $A C$ was observed in fruits of $S p O$ and $S s W$ (Fig. 3). The AC of pitaya fruit is due to the presence of both, betalains and phenolic compounds, which have the ability 

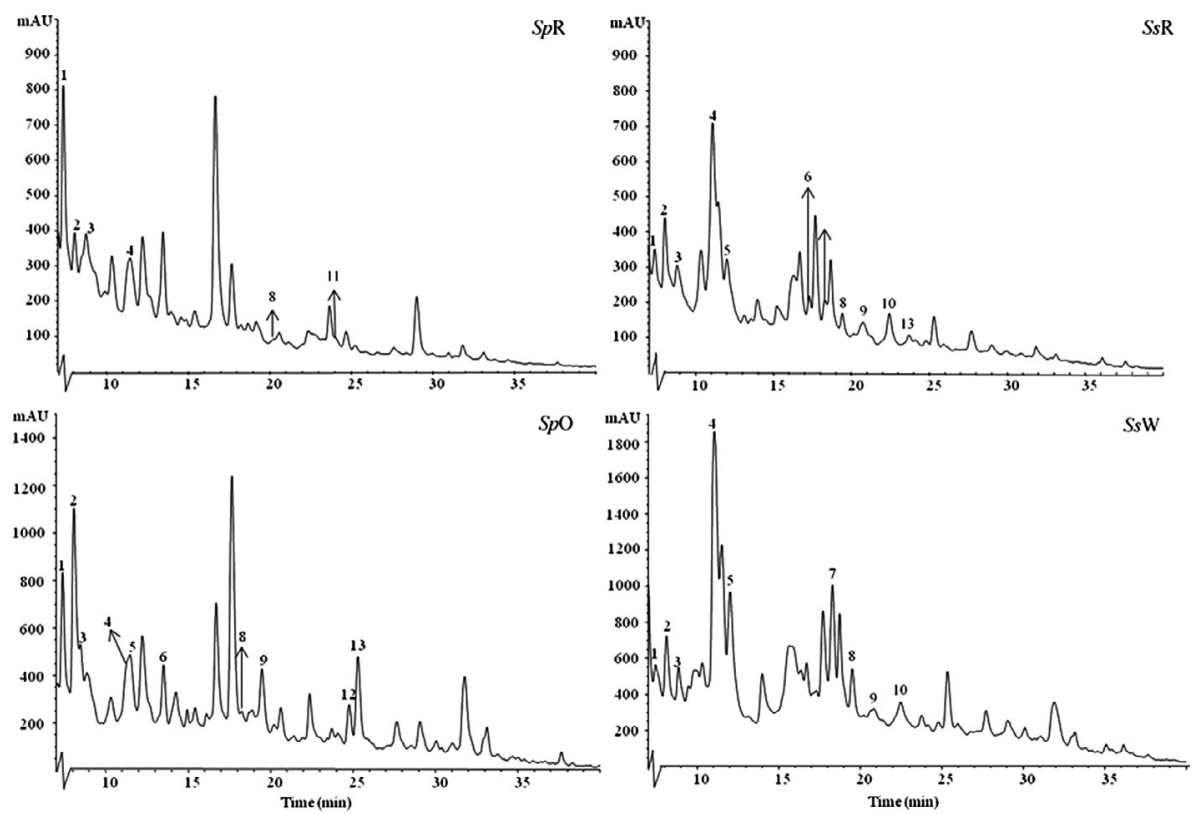

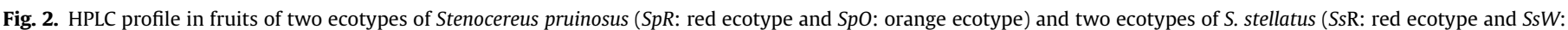
white ecotype) recorded at $280 \mathrm{~nm}$.

to donate their electrons and to scavenge the ABTS cation radical as Trolox does (Rice-Evans, Miller, \& Paganga, 1997; Butera et al., 2002). However, the interactions that occur between different types of compounds within each group, to express a particular antioxidant capacity, are not fully understood. In prickly pears of Opuntia ficus indica with yellow, red and white flesh, the AC reported with ABTS assay was of $5.31 \pm 49,4.20 \pm 0.51$ and $4.36 \pm 0.41 \mu \mathrm{mol} \mathrm{TE} / \mathrm{g}$ fresh pulp, respectively. Of the two betalains predominant in the fruits, betanin showed a much higher AC than indicaxanthin, however, the red fruit, with the highest betanin content, did not present the highest AC (Butera et al., 2002). The $A C$ of the most abundant betalain present in the fruit does not always correlate with the AC expected for the whole fruit, but rather is the result of the interaction of all the antioxidant compounds it contains.

Both, betalains and phenolic compounds could influence the AC of pitaya fruit. According to the Pearson correlation analysis, the content of total betalains was the variable that showed the highest

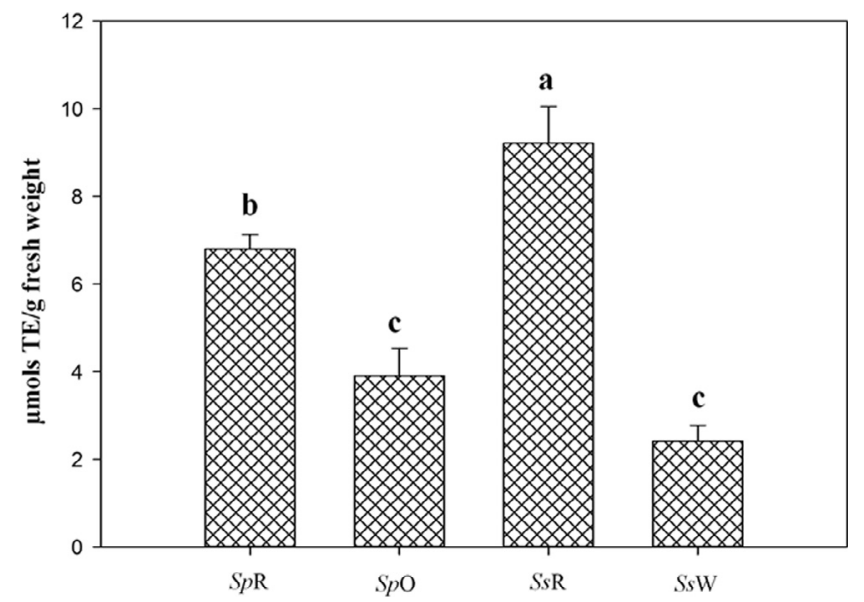

Fig. 3. Antioxidant capacity in the fruits of $S$. pruinosus (ecotypes $S p R$, with red flesh and $S p O$, with orange flesh) and of $S$. stellatus (ecotypes $S s R$, with red flesh, and $S s W$, with white flesh) determined by the ABTS assay. Means with the same letter indicate that values are not significantly different (Tukey, $\mathrm{p}<0.05$ ) positive correlation $(\mathrm{r}=0.7664, \mathrm{p}<0.01)$ with the AC of the analyzed samples; while the phenolics content showed a nonsignificant correlation (data not shown). The non- significant correlation between phenolic compounds and AC may be due to the marginal contribution of polyphenols in relation to the total amount of betalains.

The content of betalains was similar in the samples $S p R, S p O$, and $S s R$ (Table 2); however, the total content of phenolic compounds was higher in fruit of $S s R$, which may be influencing its antioxidant capacity. It should be noted that although the SsW ecotype had the highest content of phenolic compounds (Table 3 ) this was not reflected on its AC value. One plausible explanation could be that since this particular ecotype lacks betalains the contribution to the $A C$ of the total phenolics present did not outweigh the AC of ecotypes with these pigments. Similarly, the extracts from pitaya fruit can contain other reducing substances that could also influence in the antioxidant capacity. In this regard, it has been reported that in fruit where the concentration of total soluble phenolics is higher, the antioxidant capacity is mostly influenced by such compounds, despite other potent antioxidants such as vitamin $C$ and $E$, and $\beta$-carotene could be present (Jimenez-Aguilar, Lopez-Martınez, Hernandez-Brenes, Gutierrez-Uribe, \& WeltiChanes, 2015).

\section{Conclusions}

The betalains pattern of Stenocereus species fruit was different to that reported for Hylocereus spp. and Opuntia spp. The profiles and concentrations of both betalains and phenolic compounds in fruits of the two species of Stenocereus studied varied by color of flesh and among species. In red varieties, betalains were present in much higher levels than phenolic compounds, however, the contribution of these latter to the antioxidant potential of pitaya fruits seemed evident. Thus, in samples with similar betalain concentrations (i.e., SpO and SsR), significantly higher antioxidant capacity was observed in those with greater phenolic content. Furthermore, white fruits $(S s W)$, despite lacking betalains, yielded similar antioxidant values as the orange sample $S p O$ with lower phenolic content. The presence of flavanones in Stenocereus stellatus, a class 
of phenolic compounds that has been not previously reported in cacti fruits, showed the enormous wealth of phytochemicals that this genus possesses and that could be exploited in benefit to human health.

\section{Acknowledgements}

Author Leticia García-Cruz acknowledge to CONACYT, Mexico for the scholarship for her Master's studies (Registration number: 274552).

\section{References}

Balasundram, N., Sundram, K., \& Samman, S. (2006). Phenolic compounds in plants and agri-industrial by-products: Antioxidant activity, occurrence, and potential uses. Food Chemistry, 99, 191-203.

Barros, L., Dueñas, M., Carvalho, A. M., Ferreira, I. C. F. R., \& Santos-Buelga, C. (2012). Characterization of phenolic compounds in flowers of wild medicinal plants from Northeastern Portugal. Food and Chemical Toxicology, 50, 1576-1582.

Beltrán-Orozco, M. C., Oliva-Coba, T. G., Gallardo-Velázquez, T., \& Osorio-Revilla, G. (2009). Ascorbic acid, phenolic content, and antioxidant capacity of red, cherry, yellow and white types of pitaya cactus fruit (Stenocereus stellatus Riccobono). Agrociencia, 43, 153-161.

Bravo-Hollis, H., \& Sánchez-Mejorada, H. (1991). Las Cactáceas de México (2nd ed.). México: Universidad Nacional Autónoma de México. 643 p.

Butera, D., Tesoriere, L., Di Gaudio, F., Bongiorno, A., Allegra, M., Pintaudi, A. M., et al. (2002). Antioxidant activity of Sicilian prickly pears (Opuntia ficus indica) fruit extracts and reducing properties of its betalins: Betanin and indicaxanthin. Journal of Agricultural and Food Chemistry, 50, 6895-6901.

Cai, Y. Z., Xing, J., Sun, M., \& Corke, H. (2006). Rapid identification of betacyanins from Amaranthus tricolor, Gomphrena globosa, and Hylocereus polyrhizus by Matrix-Assisted Laser Desorption/Ionization Quadrupole Ion Trap Time-ofFlight Mass Spectrometry (MALDI-QIT-TOF MS). Journal of Agricultural and Food Chemistry, 54, 6520-6526.

Casas, A., Cruse-Sanders, J., Morales, E., Otero-Arnaiz, A., \& Valiente-Banuet, A. (2006). Maintenance of phenotypic and genotypic diversity in managed populations of Stenocereus stellatus (Cactaceae) by indigenous peoples in Central Mexico. Biodiversity and Conservation, 15, 879-898.

Castellanos-Santiago, E., \& Yahia, E. M. (2008). Identification and quantification of betalains from the fruits of 10 mexican prickly pear cultivars by highperformance liquid chromatography and electrospray ionization mass spectrometry. Journal of Agricultural and Food Chemistry, 56, 5758-5764.

Cejudo-Bastante, M. J., Chalaal, M., Louaileche, H., Parrado, J., \& Heredia, F. J. (2014). Betalain profile, phenolic content, and color characterization of different parts and varieties of O. ficus-indica. Journal of Agricultural and Food Chemistry, 6, 8491-8499.

Esquivel, P., Stintzing, F. C., \& Carle, R. (2007). Pigment pattern and expression of color in fruits from different Hylocereus sp. Genotypes. Innovative Food Science and Emerging Technologies, 8, 451-457.

Fathordoobady, F., Mirhosseini, H., Selamat, J., \& Abd Manap, M. Y. (2016). Effect of solvent type and ratio on betacyanins and antioxidant activity of extracts from Hylocereus polyrhizus flesh and peel by supercritical fluid extraction and solvent extraction. Food Chemistry, 202, 70-80.

García-Cruz, L., Salinas-Moreno, Y., \& Valle-Guadarrama, S. (2012). Betalaínas, compuestos fenólicos y actividad antioxidante en pitaya de mayo (Stenocereus griseus H.). Revista Fitotecnia Mexicana, 35, 1-5.

García-Cruz, L., Valle-Guadarrama, S., Salinas-Moreno, Y., \& Joaquín-Cruz, E. (2013). Physical, chemical, and antioxidant activity characterization of pitaya (Stenocereus pruinosus) fruits. Plant Foods for Human Nutrition, 68, 403-410.

Gengatharan, A., Dykes, G. W., \& Choo, W. S. (2015). Betalains: Natural plant pigments with potential application in functional foods. LWT: Food Science and Technology, 64, 645-649.

Guzmán-Maldonado, S. H., Herrera-Hernández, G., Hernández-López, D., ReynosoCamacho, R., Guzmán-Tovar, A., Vaillant, F., \& Brat, P. (2010). Physicochemical, nutritional and functional characteristics of two underutilised fruit cactus species (Myrtillocactus) produced in central Mexico. Food Chemistry, 121, 381-386.

Herrera-Hernández, M. G., Guevara-Lara, F., Reynoso-Camacho, R., \& GuzmánMaldonado, S. H. (2011). Effects of maturity stage and storage on cactus Berry
(Myrtillocactus geometrizans) phenolics, vitamin C, betalaínas and their antioxidant properties. Food Chemistry, 129, 1744-1750.

Jimenez-Aguilar, D. M., Lopez-Martınez, J. M., Hernandez-Brenes, C., GutierrezUribe, J. A., \& Welti-Chanes, J. (2015). Dietary fiber, phytochemical composition and antioxidant activity of Mexican commercial varieties of cactus pear. Journal of Food Composition and Analysis, 41, 66-73.

Kobayashi, N., Schmidt, J., Wray, V., \& Schliemann, W. (2001). Formation and occurrence of dopamine-derived betacyanins. Phytochemistry, 56, 429-436.

Luna-Morales, C. C., Aguirre-Rivera, J. R., \& Peña-Valdivia, C. B. (2001). Cultivares tradicionales mixtecos de Stenocereus pruinosus y S. stellatus. (Cactaceae). Anales del Instituto de Biología. Serie Botánica, 72, 131-155.

McGuire, R. (1992). Reporting of objective color measurements. HortScience, 27, $1254-1255$.

Montoya-Arroyo, A., Schweiggert, R. M., Pineda-Castro, M. L., Sramek, M., Kohlus, R., Carle, R., \& Esquivel, P. (2014). Characterization of cell wall polysaccharides of purple pitaya (Hylocereus sp.) pericarp. Food Hydrocolloids, 35, 557-564.

Morales, P., Barros, L., Ramirez-Moreno, E. A., Santos-Buelga, C., \& Ferreira, I. C. F. R. (2014). Exploring xoconostle by-products as sources of bioactive compounds. Food Research International, 65, 437-444.

Morales, P., Barros, L., Ramirez-Moreno, E. A., Santos-Buelga, C., \& Ferreira, I. C. F. R. (2015). Opuntia matudae Scheinvar cv. Rosa by-products as potential functional ingredients. Food Chemistry, 185, 289-297.

Ochoa-Velazco, C. E., \& Guerrero-Beltrán, J. A. (2013). Short-wave ultraviolet-C light effect on pitaya (Stenocereus griseus) juice inoculated with Zygosaccharomyces bailii. Journal of Food Engineering, 117, 34-41.

Osorio-Esquivel, O Ortiz-Moreno, A Álvarez V. B., Dorantes-Álvarez, L, \& Giusti, M. M. (2011). Phenolics, betacyanins and antioxidant activity in Opuntic joconostle fruits. Food Research International, 44, 2160-2168.

Pérez-Loredo, M. G., García-Ochoa, F., \& Barragán-Huerta, B. E. (2015). Comparative analysis of betalain content in Stenocereus stellatus fruits and other cactus fruits using Principal component analysis. International Journal of Food Properties, 19, 326-338.

Pimienta-Barrios, E., \& Nobel, P. S. (2004). Ecophysiology of the pitayo de Querétaro (Stenocereus queretaroensis). Journal of Arid Environments, 59, 1-17.

Rice-Evans, C. A., Miller, N. J., \& Paganga, G. (1997). Antioxidant properties of phenolic compounds. Trends in Plant Sciences, 2, 152-159.

Santos-Buelga, C., García-Viguera, C., \& Tomás-Barberán, F. A. (2003). On-line identification of flavonoids by HPLC coupled to diode array detection. In Methods in polyphenol analysis (pp. 92-127). Cambridge, UK: Royal Society of Chemistry.

Stintzing, F. C., \& Carle, R. (2007). Betalains-emerging prospects for food scientists. Trends in Food Science \& Technology, 18, 514-525.

Stintzing, F. C., Herbach, K. M., Mosshammar, M. R., Carle, R., Yi, W., Sellappan, S., et al. (2005). Color, betalain pattern, and antioxidant properties of cactus pear (Opuntia spp.) clones. Journal of Agricultural and Food Chemistry, 53, 442-541.

Stintzing, F. C., Schieber, A., \& Carle, R. (2002). Betacyanins in fruits from red-purple pitaya. Hylocereus polyrhizus (Weber) Brintton \& Rose. Food Chemistry, 77, $101-106$.

Strack, D., Vogt, T., \& Schliemann, W. (2003). Recent advances in betalain research. Phytochemistry, 62, 247-269.

Suh, D. H., Lee, S., Heo, D. Y., Kim, Y. S., Cho, S. K., Lee, S., \& Lee, C. H. (2014) Metabolite profiling of red and white pitayas (Hylocereus polyrhizus and Hylocereus undatus) for comparing betalain biosynthesis and antioxidant activity. Journal of Agricultural and Food Chemistry, 62, 8764-8771.

Vidal, P. J., López-Nicolás, J. M., Gandía-Herrero, F., \& García-Carmona, F. (2014). Inactivation of lipoxygenase and cyclooxygenase by natural betalains and semisynthetic analogues. Food Chemistry, 154, 246-254.

Wu, L. C., Hsu, H. W., Chen, Y. C., Chiu, C. C., Lin, Y. I., \& Ho, J. A. (2006). Antioxidant and antiproliferative activities of red pitaya. Food Chemistry, 95, 319-327.

Wybraniec, S., Nowak-Wydra, B., Mitka, K., Kowalski, P., \& Mizrahi, Y. (2007). Minor betalains in fruits of Hylocereus species. Phytochemistry, 68, 251-259.

Wybraniec, S., Platzner, I., Geresh, S., Gottlieb, H. E., Haimberg, M., Mogilniyzki, M., \& Mizrahi, Y. (2001). Betacyanins from vine cactus Hylocereus polyrhizus. Phytochemistry, 58, 1209-1212.

Wybraniec, S., Stalica, P., Spórna, A., \& Mizrahi, Y. (2010). Profiles of betacyanins in epidermal layers of grafted and light-stressed cacti studied by LC-DAD-ESI-MS/ MS. Journal of Agricultural and Food Chemistry, 58, 5347-5354.

Zou, D., Brewer, M., Garcia, F., Feunggang, J. M., Wang, J., Zang, R., et al. (2005) Cactus pear: a natural product in cancer chemoprevention. Nutrition Journal, 4, 25. 